\title{
Axonal and perikaryal involvement in chronic inflammatory demyelinating polyneuropathy
}

M Nagamatsu, S Terao, K Misu, M Li, N Hattori, M Ichimura, M Sakai, H Yamamoto, H Watanabe, S Riku, E Ikeda, J Hata, M Oda, $M$ Satake, N Nakamura, S Matsuya, Y Hashizume, G Sobue

\author{
Department of \\ Neurology, Nagoya \\ University School of \\ Medicine, Nagoya, \\ Japan \\ M Nagamatsu \\ $\mathrm{M} \mathrm{Li}$ \\ K Misu \\ N Hattori \\ M Ichimura \\ G Sobue
}

Fourth Department of Internal Medicine, Aichi Medical University, Aichi,

Japan

$\mathrm{S}$ Terao

Department of Neurology, Fujita Health University School of Medicine, Toyoake, Japan H Yamamoto

M Sakai

Department of Neurology, Nogoya Daini Red Cross Hospital, Nagoya, Japan

$\mathrm{H}$ Watanabe

Department of Neurology, Chukyo Hospital, Nagoya, Japan

S Riku

Department of Pathology, Keio University School of Medicine, Tokyo, Japan E Ikeda

J Hata

Department of Pathology, Tokyo Metropolitan

Neurological Hospital, Tokyo, Japan

M Oda

Correspondence to: Dr G Sobue, Department of Neurology, Nagoya University School of Medicine, 65 Tsurumai-cho, Showa-ku, Nagoya 466-8550, Japan. Telephone 008152741 2111; fax 0081 527442384 .

Received 9 September 1998 and in revised form 16 December 1998

Accepted 22 December 1998

\begin{abstract}
Objectives-To assess the extent of loss of myelinated nerve fibres and spinal motor neuron loss in chronic inflammatory demyelinating polyneuropathy (CIDP), a clinicopathological study was conducted on biopsied sural nerves and necropsied spinal cords from patients with CIDP.

Methods-The myelinated fibre pathology of 71 biopsied sural nerves and motor neuron pathology of nine necropsied spinal cords at L4 levels in patients with CIDP were quantitatively and immunohistochemically assessed.

Results-Myelinated nerve fibre density was significantly diminished to $65.4 \%$ of the control values $(p<0.0001)$, correlating inversely with the extent of segmental demyelination and remyelination $(r=$ $-0.43, p<0.0005)$ and duration of illness $(r=-0.31, p<0.01)$. Numbers of large spinal motor neurons in CIDP were variably but significantly diminished (range from 46.0 to $97.6 \%$ of the age matched control value $(p<0.005))$, and reactive astrogliosis was evident in the ventral horn in CIDP. The frequency of ventral horn neurons exhibiting central chromatolysis and the accumulation of phosphorylated high molecular weight neurofilament protein was significantly higher in CIDP than in controls $(p<0.01$ and $\mathbf{p}<0.05$ ).

Conclusions-The loss of nerve axons and spinal motor neurons is common in CIDP, and extensive in some cases. These neuronal and axonal losses may influence the functional prognosis in CIDP.

(F Neurol Neurosurg Psychiatry 1999;66:727-734)
\end{abstract}

Keywords: chronic inflammatory demyelinating polyneuropathy; axon loss; spinal motor neuron

The pathological hallmark of chronic inflammatory demyelinating polyneuropathy (CIDP) is segmental demyelination and mononuclear inflammatory cell infiltration in the peripheral nerves, accompanied by varying degrees of axonal degeneration, myelinated fibre loss, and endoneurial oedema. ${ }^{1}$ Regarding the pathology of the CNS in CIDP, central chromatolysis in spinal motor neurons has often been reported, ${ }^{2-6}$ and sporadic cases with a slight loss of spinal motor neurons have occasionally been documented. $^{36-9}$ Spinal motor neuron loss as well as nerve myelinated fibre loss could be important factors influencing functional recov- ery. In this study, we assessed the degree of involvement of spinal motor neurons and peripheral nerve axons in CIDP.

\section{Methods}

SPECIMENS

After informed consent was given, sural nerve biopsy specimens from 71 patients with CIDP (50 males and 21 females) were obtained at the Nagoya University School of Medicine and its affiliated hospitals over 11 years. Age at biopsy ranged from 2 to 81 years; mean (SD) age 48.5 (21.9) years. The duration of illness before biopsy ranged from 2 months to 28 years; mean (SD) 2.9 (5.8) years. The spinal cords were obtained at necropsy from nine patients with CIDP. Three of these patients were necropsied at the Nagoya University Hospital and affiliated hospitals, and others were necropsied in hospitals located throughout Japan during the past 11 years. These patients consisted of six men and three women, aged 49 to 73 years; mean (SD) 62.4 (8.9) years. Their duration of illness ranged from 4 months to 8 years. Clinical profiles of necropsy cases are summarised in table $1 .^{10}$

The diagnosis of CIDP in our study was assessed using the criteria of Barohn et $a l^{11}$ or the ad hoc subcommittee of the American Academy of Neurology. ${ }^{12}$

\section{ASSESSMENT OF SURAL NERVE BIOPSY}

Sural nerve biopsy specimens were fixed in glutaraldehyde in $0.025 \mathrm{M}$ cacodylate buffer (pH 7.4) and embedded in epoxy resin. Semithin sections were stained with toluidine blue, and the density of myelinated fibres was analysed quantitatively using a computer assisted imaging system (Luzex FS, Nireco, Tokyo, Japan). The extent of subperineurial oedema was assessed as an increase in the subperineurial space by comparing the subperineurial area to the total endoneurial area using the same imaging system. A part of the nerve specimen was processed for teased fibre analysis, and the condition of each fibre was assessed according to our previously indicated criteria. ${ }^{13}$ A portion of the nerve specimen was fixed in $10 \%$ buffered formalin and embedded in paraffin, and then processed for immunohistochemical study. Mouse monoclonal antibodies $(\mathrm{mAb})$ to human leucocyte common antigen (LCA, DAKO, Denmark; dilution, 1:50), helper/inducer T cells (CD4, Novocastra, UK; dilution, 1:10), cytotoxic/suppressor $\mathrm{T}$ cells (CD8, DAKO; dilution, 1:25), and macrophages (CD68, DAKO; dilution, 1:10) were used. The avidin-biotin-peroxidase complex 
Table 1 Clinical features of necropsied patients with CIDP

\begin{tabular}{|c|c|c|c|c|c|c|c|c|c|c|c|c|c|}
\hline \multirow[b]{2}{*}{ Patient } & \multirow[b]{2}{*}{$\begin{array}{l}\text { Age at } \\
\text { death }\end{array}$} & \multirow[b]{2}{*}{ Sex } & \multirow[b]{2}{*}{$\begin{array}{l}\text { Onset to } \\
\text { death }(y)\end{array}$} & \multirow{2}{*}{$\begin{array}{l}\text { Motor/ } \\
\text { Sensory } \\
\text { symptoms }\end{array}$} & \multirow{2}{*}{$\begin{array}{l}\text { Modified } \\
\text { Rankin score } \\
\text { (pretreatment) }\end{array}$} & \multicolumn{3}{|c|}{ Therapeutic response } & \multicolumn{2}{|l|}{ Muscle } & \multirow{2}{*}{$\begin{array}{l}\text { Modified } \\
\text { Rankin score } \\
\text { (before death) }\end{array}$} & \multirow{2}{*}{$\begin{array}{l}\text { CSF } \\
\text { protein } \\
\text { (mg/dl) }\end{array}$} & \multirow[b]{2}{*}{ Cause of death } \\
\hline & & & & & & $\begin{array}{l}\text { Cortico- } \\
\text { steroid }\end{array}$ & $\begin{array}{l}\text { Plasma- } \\
\text { phoresis }\end{array}$ & $I V I g$ & Atrophy & Weakness & & & \\
\hline 1 & 72 & M & 3.5 & $M>S$ & 4 & & + & + & 2 & 3 & 5 & 105 & Heart failure \\
\hline 2 & 55 & $\mathrm{~F}$ & 0.8 & $\mathrm{M}>\mathrm{S}$ & 3 & + & & & 2 & 3 & 5 & 800 & $\begin{array}{l}\text { Cardiovascular } \\
\text { disease }\end{array}$ \\
\hline 3 & 49 & M & 8 & $M>S$ & 3 & - & & & 3 & 3 & 4 & 99 & Pneumonia \\
\hline 4 & 68 & M & 3 & $\mathrm{M}=\mathrm{S}$ & 3 & + & & & 2 & 2 & 3 & 218 & Pneumonia \\
\hline 5 & 54 & $\mathrm{~F}$ & 0.3 & $\mathrm{M}=\mathrm{S}$ & 5 & + & & & 1 & 3 & 5 & 171 & Pneumonia \\
\hline 6 & 57 & M & 2.5 & $M>S$ & 3 & + & + & & 2 & 3 & 5 & 110 & Endocarditis \\
\hline 7 & 70 & $\mathrm{~F}$ & 1 & $M>S$ & 3 & + & & & 1 & 1 & 2 & 73 & $\begin{array}{l}\text { Cardiovascular } \\
\text { disease }\end{array}$ \\
\hline 8 & 73 & M & 0.5 & $M=S$ & 5 & + & & & 1 & 3 & 4 & 128 & Pneumonia \\
\hline 9 & 64 & $M$ & 15 & $M<S$ & 2 & + & & & 1 & 1 & 2 & NA & $\begin{array}{l}\text { Bronchitis/ } \\
\text { Meningitis }\end{array}$ \\
\hline
\end{tabular}

Modified Rankin score: $0=$ asymptomatic; $1=$ non-disabling symptoms that do not interfere with lifestyle; $2=$ minor disability symptoms that lead to some restriction of lifestyle but do not interfere with the patients' capacity to look after themselves; $3=$ moderate disability symptoms that significantly interfere with lifestyle or prevent totally independent existence; 4 = moderately severe disability symptoms that clearly prevent independent existence, although patient does not need constant attention day and night; and $5=$ severely disabled, totally dependent requiring constant attention day and night. ${ }^{10}$ Modified Rankin scores of some patients were assessed on the clinical records. Therapeutic response was evaluated as positive if the modified Rankin score improved one grade or more. Muscle atrophy and weakness were respectively assessed as 1,2, and 3 denoting mild, moderate, and severe degrees. NA=not available. The grading was made within 3 months before death.

(ABC) method was performed using a Vectastain Kit (Vector Laboratories, Burlingame, CA, USA) as described previously. ${ }^{14}$ The extent of endoneurial and epineurial inflammatory infiltrates was assessed in a blind fashion for each mAbs.

Eleven sural nerve specimens from subjects with non-neurological diseases (eight men and three women, aged 28 to 71 years; mean (SD) 44.6 (13.5) years) obtained at biopsy for transplantation or at necropsy performed within 3 hours of death were processed in the same way as the biopsy specimens from patients with CIDP, and served as controls.

ASSESSMENT OF SPINAL CORD PATHOLOGY

The spinal cord was removed at necropsy, fixed in $10 \%$ buffered formalin solution, and processed for paraffin sections. Routine histological studies with haematoxylin and eosin, KlüverBarrera, and Bodian stain were performed on lumbar spinal cord specimens. The population of spinal motor neurons was assessed as described previously. ${ }^{15}{ }^{16}$ From the rostral end of the fourth lumbar segment, up to 300 serial
$10 \mu \mathrm{m}$ thick sections were prepared, and every 10th section was stained with the KlüverBarrera technique. Photomicrographs were taken at a magnification of $\times 205$, including the left ventral horn in each stained section. The spinal ventral horn was defined as the area of grey matter ventral to a line through the central canal perpendicular to the ventral sulcus. Diameters of all neurons with obvious nucleoli were measured on photomicrographs using a particle size analyser (TGZ-3, Carl-Zeiss, Germany). The neurons were classified arbitrarily into three groups according to their diameters as large $(\geqslant 32.8 \mu \mathrm{m})$, medium sized $(\geqslant 24.8 \mu \mathrm{m}$ to $<32.8 \mu \mathrm{m})$, and small $(<24.8 \mu \mathrm{m})$ neurons. ${ }^{15}$ Neuronal numbers were expressed as the total number of cells $/ 50$ sections as described previously. ${ }^{15}{ }^{16}$ Immunohistochemical assessment was performed in the same manner as for the sural nerves. We used a $\mathrm{mAb}$ Ta-51 specific to a phosphorylated epitope of high molecular weight subunits of neurofilaments ( $\mathrm{pNFH}$; dilution, $1: 10$ ), a mAb against human glial fibrillary acidic protein (GFAP, DAKO; dilution, 1:200), human B
Department of

Neurology, Faculty of Medicine, Kyushu University, Fukuoka, Japan

M Satake

Department of Pathology, Yokohama Municipal Citizens Hospital, Yokohama, Japan

N Nakamura

Department of Diagnostic Pathology, NTT Kanto Teishin Hospital, Tokyo, Japan S Matsuya

Institute for Medical Science of Aging, Aichi Medical University, Aichi, Japan Y Hashizume
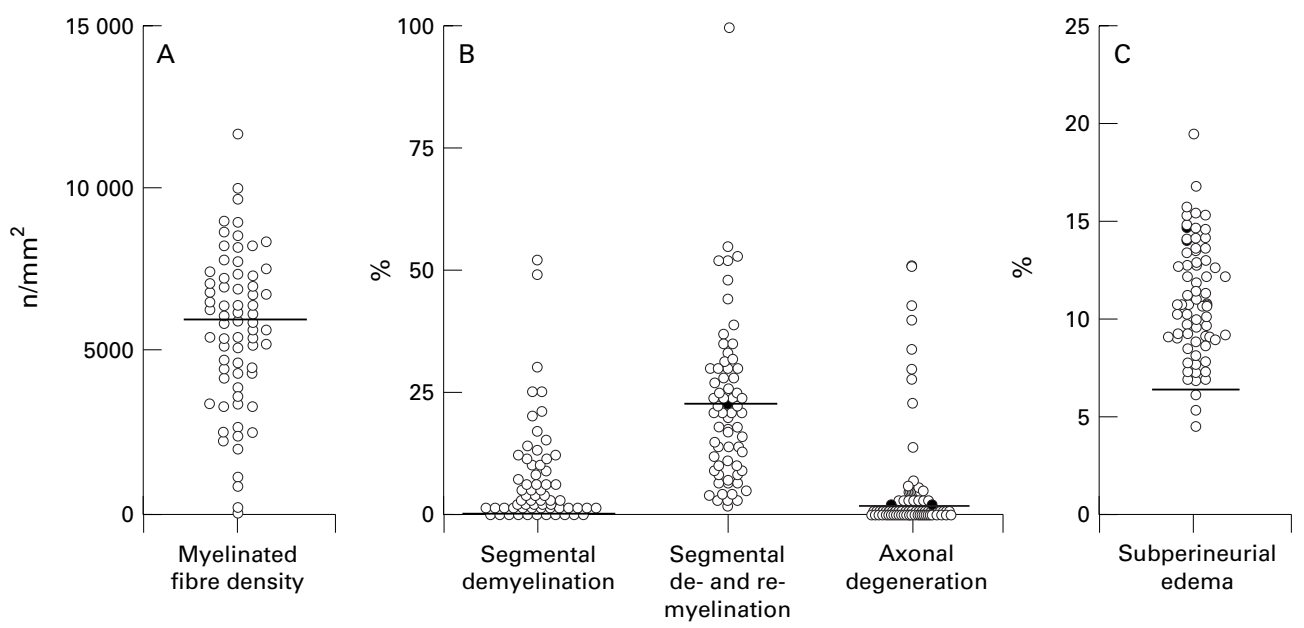

Figure 1 Myelinated fibre pathology in the sural nerves from 71 patients with CIDP. (A) Density of myelinated fibres. The bold line is the mean $-S D$ value in control nerves. The mean value in CIDP is significantly decreased compared with controls $(p<0.0001)$. (B) Teased fibre findings. The bold line is the mean $+S D$ value in control nerves. Frequency of segmental demyelination and segmental demyelination and remyelination was significantly increased compared with control values $(p<0.0005$ and $p<0.05$, respectively). (C) Subperineurial oedema. The bold line is the mean $+S D$ value in control nerves. The mean value in CIDP is significantly increased compared with controls $(p<0.0001)$. 

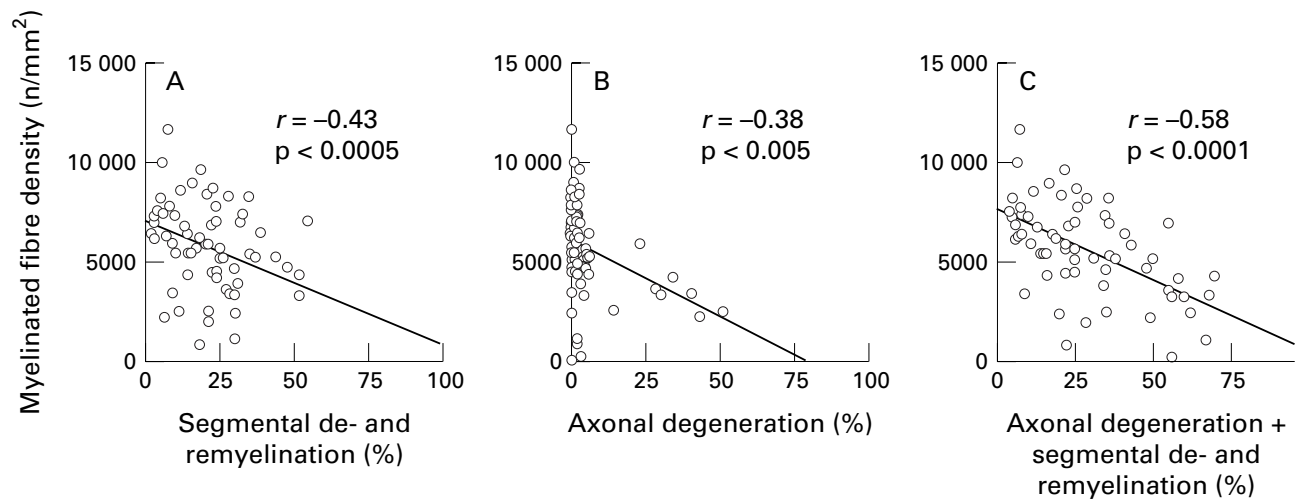

Figure 2 Correlation between myelinated fibre density and abnormalities on teased fibre studies in 71 patients with CIDP. (A) Segmental demyelination and remyelination. (B) Axonal degeneration. (C) Segmental demyelination and remyelination plus axonal degeneration. Myelinated fibre density is inversely correlated with demyelinating changes.

cells (CD20, DAKO; dilution, 1:50), and a broad range of T cells (UCHL1, DAKO; dilution, 1:125). CD68, CD4, CD8, and LCA antibodies were used in the same manner as the sural nerves. To assess the occurrence of motor neurons expressing pNFH in neuronal perikarya, Ta-51 positive ventral horn neurons with obvious nucleoli were counted, and a ratio to the total neuronal population was expressed as described previously. ${ }^{14}{ }^{17}$ Gliosis in the ventral horn was assessed using Holzer stain and immunohistochemistry for GFAP. Motor neurons satisfying the criteria for central chromatolysis by Campbell and Novick ${ }^{18}$ were designated as undergoing active central chromatolysis, and their occurrence among total neurons was estimated on Klüver-Barrera stained sections as described before. ${ }^{15}$

Spinal cords of seven subjects who died of non-neurological disorders, (aged 47 to 81 years; mean (SD) 66.6 (12.7) years), were examined in the same manner as age matched controls.

STATISTICAL ANALYSIS

Statistical analyses were by Student's $t$ test, Mann-Whitney $U$ test, and Pearson's correlation coefficient; $\mathrm{p}<0.05$ was taken as significant.

\section{Results}

SURAL NERVES

The myelinated fibre density of the sural nerves was diminished in varying degrees (mean (SD) 5679 (2370) $/ \mathrm{mm}^{2}$; significantly less than control values, $8679(1336) / \mathrm{mm}^{2} ; \mathrm{p}<0.0001$; fig 1A. The incidence of abnormalities in the teased fibre preparation was also increased to various degrees (fig $1 \mathrm{~B}$ ): 0 to $52 \%$ for segmental demyelination (mean (SD) $7.2(10.6) \%$ ); significantly greater than controls $0(0) \%$; $\mathrm{p}<0.0005 ; 0$ to $100 \%$ for segmental demyelination and remyelination (mean (SD) 23.0 $(16.6) \%)$; significantly increased compared with controls, $9.5(8.8) \% ; p<0.05$. The extent of active axonal degeneration in CIDP varied widely, ranging from 0 to $51 \%$, (mean (SD) 5.5 $(11.1) \%$ ), and $23 \%$ of the nerves showed values exceeding the mean $+2 \mathrm{SD}$ control level (controls, mean (SD) $1.7(1.4) \%$ ). The extent of subperineurial oedema in CIDP (mean

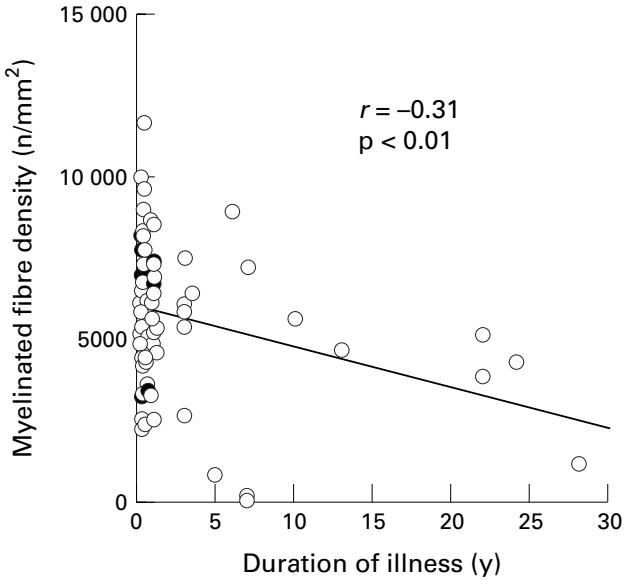

Figure 3 Correlation between myelinated fibre density in the sural nerves and duration of illness in 71 patients with CIDP. A significant inverse correlation is seen.

(SD), $11.0(3.1) \%$ ) was significantly greater than in controls (mean (SD), $4.6(1.0) \%$, $\mathrm{p}<0.0001$; fig 1C). The density of myelinated fibres was significantly inversely correlated with the extent of segmental demyelination and remyelination (fig $2 \mathrm{~A}$ ), and with the extent of segmental demyelination and remyelination plus axonal degeneration (fig 2C). Patients with a marked increase in axonal degeneration were also accompanied by a considerable myelinated fibre loss (fig 2B). Myelinated fibre loss was directly correlated with the duration of illness (fig 3), and severe fibre loss $\left(<2000 / \mathrm{mm}^{2}\right.$ in remaining fibres) was found in some patients with a duration of illness exceeding 5 years before the nerve biopsy. Myelinated fibre loss was not significantly correlated with the extent of mononuclear cellular infiltrates as assessed by immunohistochemistry. Infiltrates of LCA positive cells were found using immunohistochemistry in the endoneurium or epineurium in $72 \%$ of patients with CIDP. Infiltrates of CD 4 positive cells were found in $37 \%$, CD8 positive cells in $35 \%$, and CD68 positive cells in $67 \%$ of the nerves from patients with CIDP.

SPINAL CORDS

The mean number of large motor neurons in the unilateral L4 ventral horn in CIDP (mean (SD) 466 (99)/50 sections) was significantly diminished compared with that of age matched 

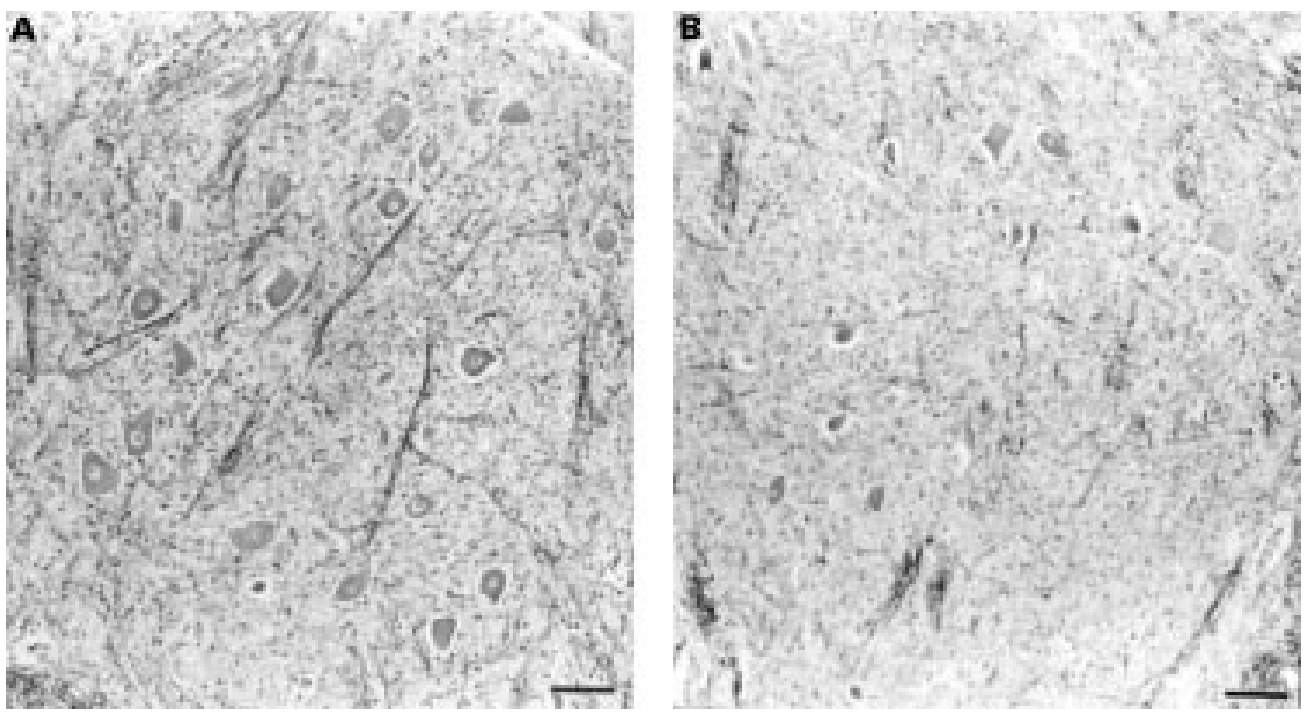

Figure 4 The ventral horn of the $L 4$ segment of the spinal cord from a control $(A)$ and from a patient with CIDP (B). Loss of ventral horn cells, especially large neurons, is evident in CIDP. Klüver-Barrera stain. Bar $=100 \mu \mathrm{m}$.

controls (mean (SD) 632 (55)/50 sections, p $<0.005$; fig 4 and 5 A). The extent of loss of large motor neurons in CIDP was highly variable, the average value being $73.7 \%$ of the controls, and the minimum value only $46 \%$ of the mean control value (fig 4 and 5A). The small neurons were also significantly depopulated in CIDP, although to a lesser extent (fig 5C). The number of medium sized neurons was not sig-

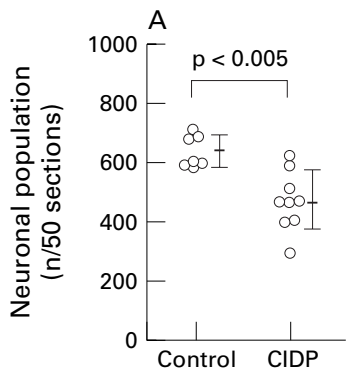

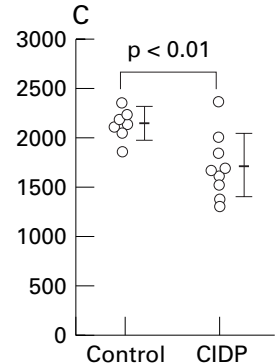

Figure 5 The population of large $(A)$, medium sized $(B)$, and small $(C)$ spinal motor neurons in 50 sections of the left $L 4$ segment of the spinal cord. Numbers of large neurons are significantly reduced in CIDP compared with age matched controls $(p<0.005)$. Small neurons are also decreased slightly but significantly $(p<0.01)$. nificantly decreased (fig 5B). The frequency of ventral horn neurons exhibiting central chromatolysis and accumulations of pNFH was significantly higher in CIDP than in controls $(\mathrm{p}<0.01$ and $\mathrm{p}<0.05$, respectively; fig 6 and table 2). Reactive astrogliosis in the ventral horn was also more prominent in CIDP (table 2). Neuronophagia was occasionally demonstrated by immunohistochemistry using CD68, but lymphocytes positive for CD4, CD8, or UCHL1 were not found in the ventral horns of CIDP. Varying degrees of myelinated fibre loss in the dorsal columns were seen at the L4 level in five of nine patients (table 2).

\section{Discussion}

Our study showed that myelinated nerve fibre loss is common in CIDP, and that it is correlated with the extent of demyelination and remyelination on teased fibre analysis as well as with the duration of illness. These findings indicate that both the intensity of the inflammatory demyelinating process and the longevity of

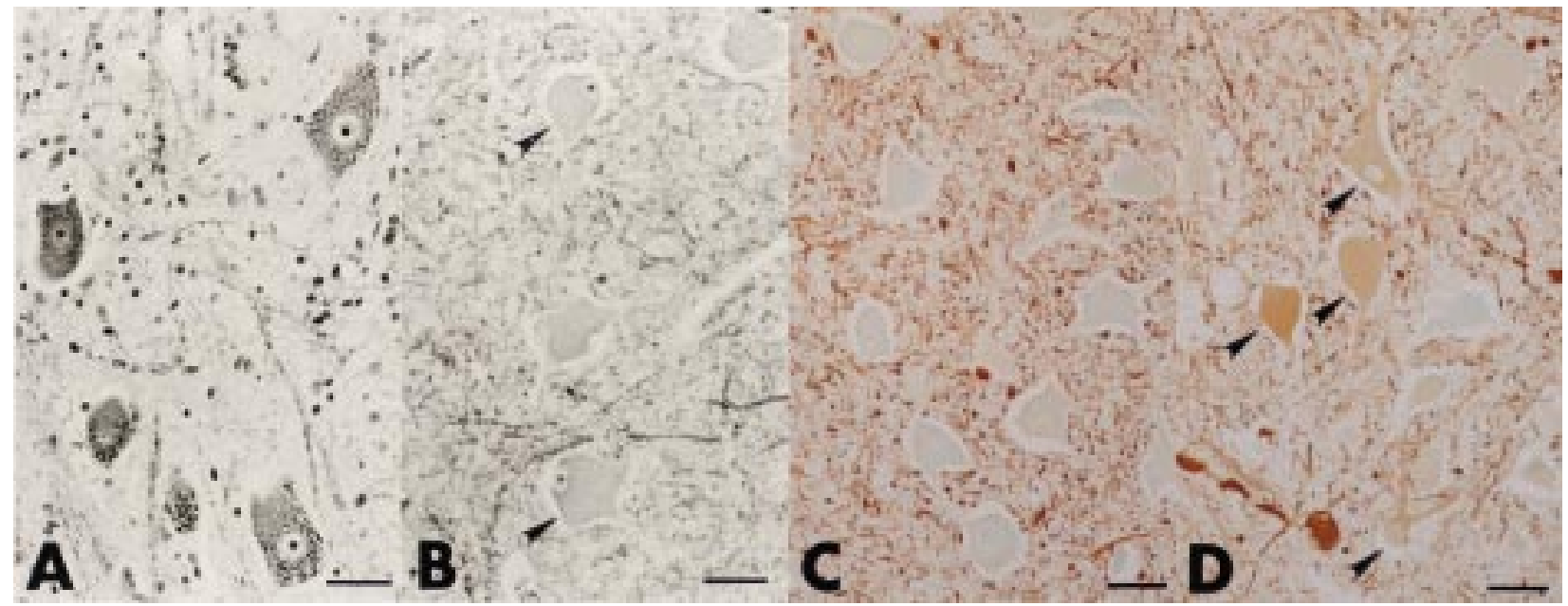

Figure 6 The ventral horn of the L4 segment spinal cord from a control ( $A$ and $C$ ) and a patient with CIDP (B and D). A and B, Klüver-Barrera stain; $C$ and D, immunohistochemistry using monoclonal antibody Ta-51, recognising phosphorylated epitope of the high molecular weight subunits of neurofilaments (pNFH). Central chromatolysis (arrowheads in B) and accumulation of pNFH (arrowheads in D) in the cell bodies of spinal motor neurons are evident in the patient with CIDP. Bar $=50 \mu \mathrm{m}$. 
Table 2 Pathological features of the spinal cord (L4) in patients with CIDP

\begin{tabular}{|c|c|c|c|c|c|c|c|c|}
\hline \multirow[b]{2}{*}{ Patient } & \multicolumn{4}{|c|}{ Population of left ventral horn neurons (No /50 sections) } & \multirow[b]{2}{*}{$\begin{array}{l}\text { Ta-51-positive } \\
\text { ventral horn neurons }\end{array}$} & \multirow[b]{2}{*}{$\begin{array}{l}\text { Central chromatolysis } \\
\text { of ventral horn neurons }\end{array}$} & \multirow[b]{2}{*}{$\begin{array}{l}\text { Reactive astrogliosis in } \\
\text { ventral horn }\end{array}$} & \multirow[b]{2}{*}{$\begin{array}{l}\text { Degeneration of } \\
\text { dorsal columns }\end{array}$} \\
\hline & Large & $\begin{array}{l}\text { Medium } \\
\text { sized }\end{array}$ & Small & Total & & & & \\
\hline 1 & 291 & 242 & 1296 & 1829 & +2 & +2 & +3 & +1 \\
\hline 2 & 394 & 433 & 1369 & 2196 & +2 & +2 & +1 & 0 \\
\hline 3 & 403 & 439 & 1668 & 2510 & +2 & +2 & +3 & +3 \\
\hline 4 & 461 & 477 & 1604 & 2542 & +1 & 0 & +3 & 0 \\
\hline 5 & 464 & 423 & 1525 & 2412 & +1 & +2 & +1 & +1 \\
\hline 6 & 467 & 491 & 2007 & 2965 & +1 & 0 & +2 & 0 \\
\hline 7 & 508 & 640 & 1841 & 2989 & 0 & +2 & +1 & 0 \\
\hline 8 & 585 & 521 & 1687 & 2793 & +1 & +1 & +3 & +1 \\
\hline 9 & 617 & 729 & 2368 & 3714 & +1 & +2 & +1 & +1 \\
\hline Control $(\mathrm{n}=7)$ & $632(55)$ & $567(83)$ & $2135(156)$ & $3335(185)$ & & & & \\
\hline
\end{tabular}

The diameter of large neurons: $\geqslant 32.8 \mu \mathrm{m}$; medium sized neurons: $\geqslant 24.8-<32.8 \mu \mathrm{m}$, small neurons: $<24.8 \mu \mathrm{m}$. The control data were obtained from seven patients who died of non-neurological diseases at 49 to 73 years of age, and expressed as mean (SD). Values $<$ mean -3 SD of controls are in bold. The degrees of Ta- 51 positive neurons were determined by the criteria: $0=<5 \%$ of the total population; $+1=\geqslant 5-<12.5 \%$; $+2=\geqslant 12.5 \%$. The extent of central chromatolysis was determined as: $0=<5 \% ;+1=\geqslant 5-<10 \% ;+2=\geqslant 10 \%$. Reactive astrogliosis was evaluated semiquantitatively as 0 (minimal); +1 (mild); +2 (moderate); +3 (severe), using a Holzer stain and immunohistochemistry for glial fibrillary acidic protein. Degeneration of the dorsal columns was assessed semiquantitatively as 0 (none to minimal); +1 (mild); +2 (moderate); +3 (severe).

the disease process are the factors influencing the severity of myelinated fibre loss.

The precise mechanism of nerve fibre loss in CIDP is unknown. In Guillain-Barré syndrome, axonal degeneration has been found in addition to macrophage mediated segmental demyelination in severe nerve lesions. ${ }^{19} \mathrm{Immu-}$ nohistochemical study showed antibody and complement mediated attacks on the axolemma of nerve fibres in a Chinese series of axonal Guillain-Barré syndrome, ${ }^{20}$ suggesting that axonal damage can occur as a primary process. However, because antibody and complement deposits in nerves from patients with CIDP are rare, ${ }^{21-26}$ axonal injury and subsequent fibre loss may be caused by a different mechanism from that suggested in the Chinese series of axonal Guillain-Barré syndrome.

In experimental allergic neuritis (EAN) $)^{27-30}$ and chronic EAN, ${ }^{31-33}$ models of acute and chronic inflammatory demyelinating neuropathy, axonal degeneration has also been found. Hahn et al and Madrid and Wisniewski reported that the extent of axonal degeneration in nerve roots corresponded to the degree of inflammation and demyelination in their models of EAN. ${ }^{28-30}$ Moreover, Said et al also documented axonal degeneration distal to the demyelinated nerve segments by the intraneural injection of antiserum from EAN rabbits. ${ }^{34}$ Soluble factors such as proteases, phospholipases, lymphotoxins, or tumour necrosis factor- $\alpha(\mathrm{TNF}-\alpha)$ from infiltrating mononuclear cells are supposed to be responsible for axonal degeneration in EAN. ${ }^{28} 2936$ Meanwhile, in biopsied nerves from patients with CIDP, macrophages express TNF- $\alpha$ when attached to myelinated fibres. ${ }^{37}$ Some of the infiltrating macrophages in the endoneurium as seen in the present study might contribute to axonal damage by releasing soluble factors such as TNF- $\alpha$.

In our study, the duration of illness is another factor influencing the extent of myelinated fibre loss. Severe myelinated fibre loss in the sural nerves was found in patients with CIDP associated with marked onion bulb formation, ${ }^{38}$ suggesting that the longstanding, repeated inflammatory demyelinating process is related to myelinated fibre loss. On the other hand, myelin regulates axonal properties such as the focal number, spacing, and phosphorylation level of neurofilaments, axonal calibre, and slow axonal transport. ${ }^{39}$ Therefore, longstanding, repetitive, or persistent demyelination itself might play some part in the process of axonal damage by influencing axonal properties. Actually, hereditary demyelinating neuropathies with abnormal myelin protein genes such as Charcot-Marie-Tooth disease type $1 \mathrm{~A}$ and $1 \mathrm{~B}$, and Déjèrine-Sottas disease are often accompanied by a considerable degree of myelinated fibre loss during a lengthy process. $^{41}$

The most striking finding in our study was the spinal motor neuron loss in CIDP, which was extensive in some patients. The average loss of one fourth of the large spinal motor neurons, corresponding to $\alpha$-motor neurons, with a maximum loss of one half in our necropsied series, is more severe than so far inferred. The loss of spinal motor neurons was also evidenced by astrogliosis occurring in the lateral and medial nuclei of the ventral horn, particularly when the loss of these neurons was extensive. Muscle weakness and atrophy were pronounced in patients with extensive spinal motor neuron loss (table 1). This finding indicates that the residual disability in patients with CIDP, especially muscle wasting, is in some way related to spinal motor neuron loss.

Loss of large motor neurons has been reported a long time after limb amputation in humans and cats, ${ }^{42-44}$ suggesting that longstanding axonal damage may secondarily induce spinal motor neuron loss. Nerve cells are also supposed to be lost when axonal damage occurs close to the cell body. ${ }^{19}$ Loss of large motor neurons in the spine has been found in necropsied patients with Guillain-Barré syndrome accompanying marked proximal axonal involvements. ${ }^{15}$ In our series of CIDP, the absence of inflammatory lymphocytic infiltrates in the ventral horn suggests that the ventral horn is not the primary site of inflammation, and that longstanding or proximal motor axonal damage might cause spinal motor neuron loss. An increased rate of central chromatolysis in the spinal motor neurons also suggests the axonal involvement of motor nerves. In addition, an increased accumulation of $\mathrm{pNFH}$ in the perikarya of spinal motor 
neurons may also support this view. $\mathrm{pNFH}$ accumulation in the spinal motor neurons has been shown in a wide variety of pathological conditions including amyotrophic lateral sclerosis, ${ }^{14} 17$ toxic neuropathies, ${ }^{45}$ and experimental nerve crush. ${ }^{46}$ In most cases, a certain degree of impairment of axonal transport is speculated to underlie pNFH accumulation.

Small neurons in the intermediate zone of the ventral horn, corresponding to interneurons, were mildly but significantly decreased in CIDP. The background mechanism of this loss of small neurons is uncertain. Suzuki et $a l^{43}$ have reported a decrease in small neurons in the cervical intermediate zone as well as in large neurons on the opposite site in a necropsy case studied years after a proximal amputation of one arm, suggesting that contralateral interneurons may be damaged by transneuronal degeneration after loss of large neurons. Small neurons in the intermediate zone in our patients with CIDP might have been lost by a similar mechanism. However, as the degree of loss of small neurons in patients with CIDP was mild, this finding should be confirmed by studying additional cases of CIDP.

In summary, we showed that loss of spinal motor neurons is common in CIDP, and that substantial neuron loss may occur in some cases. Myelinated nerve fibre loss also occurred and was correlated with the extent of segmental demyelation and remyelination, and the duration of illness. These findings are important regarding the long term functional prognosis of CIDP. Ultimately, prevention of these neuronal and axonal losses would be another therapeutic goal in CIDP.

This work was performed in collaboration with Drs T Ando and T Yanagi (Department of Neurology, Nagoya Daini Red Cross Hospital, Nagoya), Drs E Isozaki and R Okiyama (Department of Neurology, Tokyo Metropolitan Neurological Hospital, Tokyo), Drs N Takahashi and K Kono (Department of Neurology, Toki General Hospital, Toki), Drs Y Washimi and C Mabuchi (Department of Neurology, Nagoya Ekisaikai Hospital, Nagoya), Drs K Mano and H Watanabe (Department of Mokuno (Department of Neurology, Toyohashi Municipal Hospital, Toyohashi), Drs M Konagaya and Y Matsuoka (Department of Neurology, Suzuka National Hospital, Suzuka), Drs T Yasuda and N Murakami (Department of Neurology, National Sanatorium Higashi Nagoya Hospital, Nagoya), Dr E Mukai (Department of Neurology, Nagoya National Hospital, Nagoya), Dr T Sakakibara (Department of Neurology, Chubu Nosai Hospital, Nagoya), Dr T Kameyama (Department of Neurology, Gifu Prefectural Tajimi Hospital, Tajimi), Dr S Neurology, Gifu Prefectural Tajimi Hospital, Tajimi), Dr S Ikeda (Department of Medicine, Shinshu University School of Medicine, Matsumoto), Dr A Kawaoi (Department of Pathology, Yamanashi Medical School, Nakakoma), Dr M Sasahara (Department of Pathology, Shiga University of Medical Science, Otsu). We are grateful to Dr J Q Trojanowski (Departments of Pathology \& Laboratory Medicine, University of Pennsylvania School of Medicine) for providing the monoclonal antibody $\mathrm{Ta}-51$. We are also grateful for the expert technical assistance of Ms Sugiko Yokoi. This work was partly supported by grants from the Ministry of Welfare and Health of Japan, and by a Centre of Excellence grant from the Ministry of Education, Science, and Culture of Japan.

1 Dyck PJ, Prineas J, Pollard J. Chronic inflammatory demyelinating polyradiculoneuropathy. In: Dyck PJ, Thomas PK, Griffin JW, et al, eds. Peripheral neuropathy. 3rd ed. Philadelphia: WB Saunders, 1993:1498-517.

2 Goto Y, Hamaguchi K, Hirai S, et al. Chronic polyneuritis with repeated remissions and exacerbations: report of case with autopsy findings. Clinical Neurology (Tokyo) 1969;9:239-47.

3 Dyck PJ, Lais AC, Ohta M, et al. Chronic inflammatory demyelinating polyradiculoneuropathy. Mayo Clin Proc 1975;50:621-37.

4 Tohgi $\mathrm{H}$, Mannen $\mathrm{T}$, Tsukagoshi $\mathrm{H}$, et al. Idiopathic chronic polyneuritis. A clinical and pathological study of two cases. Neurol Med (Tokyo) 1975;2:49-56. 5 Torvik A, Lunder T. A case of demyelinating polyneuropa-
thy resembling Guillain-Barré syndrome. I Neurol Sci thy resembling

6 Sobue G, Terao S, Hayashi F, et al. Involvement of the ventral horn cells in Guillain-Barré syndrome and chronic inflammatory demyelinating polyradiculoneuritis. Clinical Neurology (Tokyo) 1992;32:447-50.

7 Green LN, Herzog I. A case of hypertrophic interstitial neuritis coexisting with dementia and cerebellar degeneration. 7 Neuropathol Exp Neurol 1965;24:682-95.

8 Tsukagoshi $\mathrm{H}$, Yanagisawa N, Oguchi K. Morphometric quantification of the cervical limb motor cells in various neuromuscular diseases. F Neurol Sci 1980;47:463-72.

9 Matsuda M, Ikeda S, Sakurai S, et al. Hypertrophic neuritis due to chronic inflammatory demyelinating polyradiculoneuroapthy (CIDP): a postmortem pathologic study. Muscle Nerve 1996;19:163-9.

10 Simmons Z, Albers JW, Bromberg MB, et al. Presentation and initial clinical course in patients with chronic inflammatory demyelinating polyradiculoneuropathy: comparison of patients without and with monoclonal gammopathy. Neurology 1993;43:2202-9.

11 Barohn RJ, Kissel JT, Walmolts JR, et al. Chronic inflammatory polyradiculoneuroapthy. Clinical characteristics,
course, and recommendations for diagnostic criteria. Arch Neurse, and recommend $1989 ; 46: 878-84$.

12 Ad Hoc Subcommittee of the American Academy of Neurology AIDS Task Force. Research criteria for diagnosis of chronic inflammatory demyelinating polyneuropathy (CIDP). Neurology 1991;41:617-8.

13 Sobue G, Hashizume Y, Mukai E, et al. X-linked recessive bulbospinal neuronopathy: a clinicopathological study. Brain 1989;112:209-32.

14 Sobue G, Hashizume Y, Yasuda T, et al. Phosphorylated high molecular weight neurofilament protein in lower motor neurons in amyotrophic lateral sclerosis and other neurodegenerative disease involving ventral horn cells. Acta Neuropathol (Berl) 1990;79:402-8.

15 Sobue G, Li M, Terao S, et al. Axonal pathology in Japanese Guillain-Barré syndrome: a study of 15 autopsied cases. Neurology 1997;48:1694-700.

16 Terao S, Li M, Hashizume Y, et al. Upper motor neuron lesions in stroke patients do not induce anterograde ransneuronal degeneration in spinal anterior horn cells. Stroke 1997;28:2553-6.

17 Itoh T, Sobue G, Ken E, et al. Phosphorylated high molecular weight neurofilament protein in the peripheral motor, sensory and sympathetic neuronal perikarya: systemdependent normal variations and changes in amyotrophic lateral sclerosis and multiple system atrophy. Acta Neuropathol (Berl) 1992;83:240-5.

18 Campbell B, Novick R. A quantitative method for the study of chromatolysis. Proc Soc Exp Biol Med 1946;61:425-7.

19 Aranson BG, Soliven B. Acute inflammatory demyelinating polyradiculoneuropathy. In: Dyck PJ, Thomas PK, Griffin JW, et al, eds. Peripheral neuropathy. 3rd ed. Philadelphia: WB Saunders, 1993:1437-97.

20 Hafer-Macko C, Hsieh ST, Li CY, et al. Acute motor axonal neuropathy: an antibody-mediated attack on axolemma. Ann Neurol 1996;40:635-44.

21 Dalakas MC, Engel WK. Immunoglobulin and complement deposits in nerves of patients with chronic relapsing polyneuropathy. Arch Neurol 1980;37:637-40.

22 Hays AP, Lee SSL, Latov N. Immune reactive C3d on the surface of myelin sheaths in neuropathy. $\mathcal{F}$ Neuroimmunol 1988;18:231-44

23 McCombe PA, Pollard JD, McLeod JG. Chronic inflammatory demyelinating polyradiculoneuropathy. In: Assal JPH, Liniger C, eds. Peripheral neuropathies: what is significantly new? Padova: Liviana Press, 1989:545-57.

24 Schenone A, De Martini I, Tabaton M, et al. Direct immunofluorescence in sural nerve biopsies. Eur Neurol 1988;28: $262-9$.

25 Small GA, Lovelace RE. Chronic inflammatory demyelinating polyneuropathy. Semin Neurol 1994;13:305-12.

26 Matsumuro K, Izumo S, Umehara F, et al. Chronic inflammatory demyelinating polyneuropathy: histological and immunohistological studies on biopsied sural nerves. $f$ Neurol Sci 1994;127:170-8

27 King RHM, Thomas PK, Pollard JD. Axonal and dorsal root ganglion cell changes in experimental allergic neuritis. Neuropathol Appl Neurobiol 1977;3:471-86.

28 Madrid RE, Wisniewski HM. Axonal degeneration in demyelinating disorders. F Neurocytol 1977;6:103-17.

29 Hahn AF, Feasby TE, Steele A, et al. Demyelination and axonal degeneration in Lewis rat experimental allergic neu-
ritis depend on the myelin dosage. Lab Invest 1988;59:11525.

30 Hahn AF, Feasby TE, Lovgren D, et al. Adoptive transfer of experimental allergic neuritis in the immune suppressed host. Acta Neuropathol (Berl) 1993;86:596-601.

31 Harvey GK, Pollard JD, Schindhelm K, et al. Chronic experimental allergic neuritis. An electrophysiological and histological study in the rabbit. F Neurol Sci 1987;81:21525.

32 Lassmann H, Fierz W, Neuchrist C, et al. Chronic relapsing experimental allergic neuritis induced by repeated transfer of P2-protein reactive $T$ cell lines. Brain 1991;114: 429-42.

33 Adam AM, Atkinson PF, Hall SM, et al. Chronic experimental allergic neuritis in Lewis rats. Neuropathol Appl Neurobiol 1989;15:249-64. 
34 Said G, Saida K, Saida T, et al. Axonal lesions in acute experimental demyelination: a sequential teased nerve fiber experimental demyelination: a sec
study. Neurology 1981;31:413-21.

35 Said G, Hontebeyrie-Jaskowicz M. Nerve lesions induced by macrophage activation. Res Immunol 1992;143: 589-99.

36 Redford EG, Hall SM, Smith KJ. Vascular changes and demyelination induced by the intraneural injection of tumor necrosis factor. Brain 1995;118:869-78.

37 Oka N, Akiguchi I, Kawasaki T, et al. Tumor necrosis factor- $\alpha$ in peripheral nerve lesions. Acta Neuropathol (Berl) 1998;95:57-62.

38 Mizuno K, Nagamatsu M, Hattori N, et al. Chronic inflammatory demyelinating polyradiculoneuropathy with diffuse and massive peripheral nerve hypertrophy: distinctive clinical and magnetic resonance imaging features. Muscle Nerve 1998:21:805-8.

39 De Waegh SM, Lee VMY, Brady ST. Local modulation of neurofilament phosphorylation, axonal caliber, and slow neurofilament phosphorylation, axonal caliber, and slow 1992;68:451-63.

40 Hsieh ST, Kidd GJ, Crawford TO, et al. Regional modulation of neurofilament organization by myelination in normal axons. I Neurosci 1994;14:6392-401.
41 Dyck PJ, Ellefson RD, Lais AC, et al. Histologic and lipid studies of sural nerves in inherited hypertrophic neuropathy: preliminary report of a lipid abnormality in nerve and liver in Déèrine-Sottas disease. Mayo Clin Proc 1970;45:286-327

42 Kawamura Y, Dyck PJ. Permanent axotomy by amputation results in loss of motor neurons in man. $\mathcal{F}$ Neuropathol Exp Neurol 1981;40:658-66.

43 Suzuki H, Oyanagi K, Takahashi H, et al. Evidence for transneuronal degeneration in the spinal cord in man: a quantitative investigation of neurons in the intermediate zone after long-term amputation of the unilateral upper arm. Acta Neuropathol (Berl) 1995;89:464-70.

44 Barron KD, Cova J, Scheibly ME, et al. Morphometric measurements and RNA content of axotomized feline cervical motoneurons. $\mathcal{f}$ Neurocytol 1982;11:707-20.

45 Troncoso JC, Sternberger NH, Sternberger LA, et al. Immunohistochemical studies of neurofilament antigens in the neurofibrillary pathology induced by aluminum. Brain Res 1986;364:295-300.

46 Moss TH, Lewkowicz SJ. The axon reaction in motor and sensory neurons of mice studied by a monoclonal antibody marker of neurofilament protein. F Neurol Sci 1983;60:267-

\section{NEUROLOGICAL STAMP}

\section{Stjepan Betlheim (1898-1970)}

The Croatian neuropsychiatrist Stjepan Betlheim was born in Zagreb in 1898. He began his medical studies in Graz and graduated at the University of Vienna in 1922 . He specialised in neuropsychiatry in Vienna, Berlin, Zürich, and Paris. In Vienna he worked in the neuropsychiatric clinic headed by Professor J Wagner-Jauregg. During his specialisation, he published six articles in distinguished Austrian and German neurological or neuropsychiatric journals. The article he wrote in collaboration with Heinz Hartmann, Über Fehlreaktionen bei der Korsakoffschen Psychose (On parapraxes in the Korsakow psychosis), published in Arch $f$ Psychiat u Nervenkrank (1925;72:27586 ) is known best. As a medical student, Betlheim showed interest in psychoanalysis and attended Freud's lectures. His educators in psychoanalysis were Paul Schilder, Helen Deutsch, Sandor Rado, and Karen Horney. He returned to Zagreb in 1928, and began work as neuropsychiatrist. In the same year he founded the station for mental-hygiene. $\mathrm{He}$ continued working as a psychoanalyst in his private practice. He gave many public lectures, and wrote popular articles on psychoanalysis. In 1941, after the German and Italian armies occupied Yugoslavia, the profascist quisling Ante Pavelić became the president of Croatia. Dr I Petrić, the Minister of health (16 April 1941 to 10 October 1942) sent the group of mostly Jewish physicians and their families, to Bosnia, in the region with endemic syphilis, aimed at protecting them from prosecution and deportation to camps. Betlheim very soon voluntarily joined Marshal Tito's army - the antifascist movement-with his little daughter Ruth and wife Marie Luise, neé Morgenroth. After the second world war he returned to Zagreb and became Professor of Neuropsychiatry in 1959. He wrote the first Croatian psychiatric textbook (1959), the book Neuroze $i$ njihovo liječenje (The treatment of neuroses, 1963), the articles for Medicinska enciklopedija (Medical Encyclopedia, 1957), and also wrote for numerous

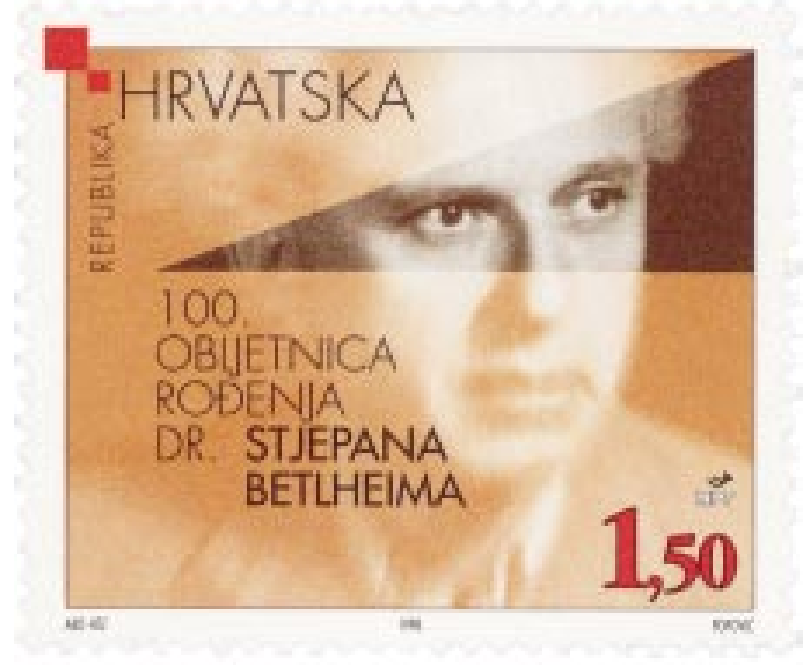

Croatian and foreign medical journals. He was a propagator of psychoanalysis, psychoanalytic psychotherapy, and group analysis not only in Croatia but also in other republics of the former Yugoslavia. Betlheim thought that neurology and psychiatry were two branches of medicine which had many connections and there was a need for neuropsychiatry. He was a member of the Vienna Psychoanalytic Society from 1928 to 1938, and of the International Psychoanalytical Association since 1952, the New York Academy of Sciences, The Royal Society of Medicine (London), Group-Analytic Society (London), and French Psychosomatic Society. For many years he was the WHO Consultant for Mental Health. In 1998, Croatia commemorated the 100th anniversary of his birth with a stamp.

IVAN BUZOV

KBC, Clinic for Medical Psychology, Kišpatićeva12, 10000 Zagreb, Croatia 